\title{
Traction resistance of a ripper with a current distribution line
}

\author{
Zafar Batirov*, Shuhrat Sharipov, Yokubjon Mahmudov, Shakhboz Azizov, and Obid \\ Mamadiyorov \\ Karshi Engineering Economic Institute, Karshi, Uzbekistan
}

\begin{abstract}
The pipeline distributor carries out deep loosening of the soil and three-tier fertilization. The study aims to determine the traction resistance of the working body of the ripper with a distribution pipe. The study uses the basic provisions of mathematics, theoretical mechanics, and agricultural mechanics. The method of calculating the traction resistance of the cultivator-fertilizer equipped with pipelines-distributors for three-tier fertilization is presented. The components of the balance of traction resistance are determined. Analytical dependencies are obtained for determining the traction resistance of the working body of the ripper with a distribution pipe. It has been established that the traction of the ripper working body with the fertilizer distributor depends on the physical and mechanical properties of the soil, the blade thickness and length of the chisel blade, the length of the working surface of the share, the angle of crumbling and the solution of the share, the width of the working body and the speed of movement. The traction resistance of the pipeline is $12-12.5 \%$ of the traction resistance of the rack and $4-5 \%$ of the total traction resistance of the ripper working body.
\end{abstract}

\section{Introduction}

The development of machines for tillage, fertilization, sowing, and harvesting of agricultural crops, as well as the study of the processes of interaction of working bodies with the processed material, is considered in works F.Mamatov [1-23], U.Umurzakov [4, 19], B.Mirzaev [4-12], [14-23], D.Chuyanov [5], H.Ravshanov [4-6, 20], H.Fayzullaev [5], N.Aldoshin $[4,5,6,20]$, E.Eshdavlatov $[1,22]$ and others.

Technologies and technical means for applying mineral fertilizers to the development layer of the root system of plants are some of the important issues in the production of agricultural crops. Also, one of the important tasks in agriculture is the development of technical means for the formation of ridges with the simultaneous introduction of mineral fertilizers in the zone of development of the root system of plants [8, 24]. In agricultural production, special attention is paid to reducing labor and energy costs, saving resources based on advanced technologies, and developing high-performance agricultural machines $[8,24-26]$.

The advanced farms of the republic have long proved the possibility of obtaining high

*Corresponding author: botirov1972@inbox.ru 
and sustainable cotton yields with the systematic and correct use of mineral and organic fertilizers against the background of high agricultural technology. Effective use of increasing doses of mineral fertilizers from year to year is achieved in compliance with scientifically-based terms and norms of fertilizer application for certain soil and climatic conditions of cotton-growing areas.

In the proposed technology, the soil is first loosened along the sowing line to a depth of up to $35 \mathrm{~cm}$ with rippers equipped with distribution pipes, and fertilizers are applied in three tiers at a time: to a depth of $16-18 \mathrm{~cm}, 28-30 \mathrm{~cm}$ and $40-45 \mathrm{~cm}$. Then ridges are formed along the fertilizer application line [28]. This technology is carried out in the fall on a prepared field for the formation of ridges: after harvesting cotton stalks, plowing with two-tier plows to a depth of $35-40 \mathrm{~cm}$ or plowing to a depth of $30 \mathrm{~cm}$ with soil deepening by $10-15 \mathrm{~cm}$, chiseling, and harrowing. The process of operation of the combined unit is as follows: first, the ripper loosens the soil to a depth of 30-35 cm. Simultaneously loosening tool provider mounted on the rear of the rack cultivator, fertilizer is made in three layers. Then the comb makers form ridges along the fertilizer application line [8].

The proposed technology provides for the tiered application of mineral fertilizers for cotton seeds, i.e., $100 \%$ of their placement in the zone of distribution of the plant's root system with the simultaneous formation of ridges.

\section{Methods}

The main provisions of mathematics, theoretical mechanics, and agricultural mechanics are used in the study. To ensure this technology, we have developed an experimental ripperfertilizer equipped with distribution lines for three-tier fertilizer application with a row spacing of $90 \mathrm{~cm} \mathrm{[24].}$
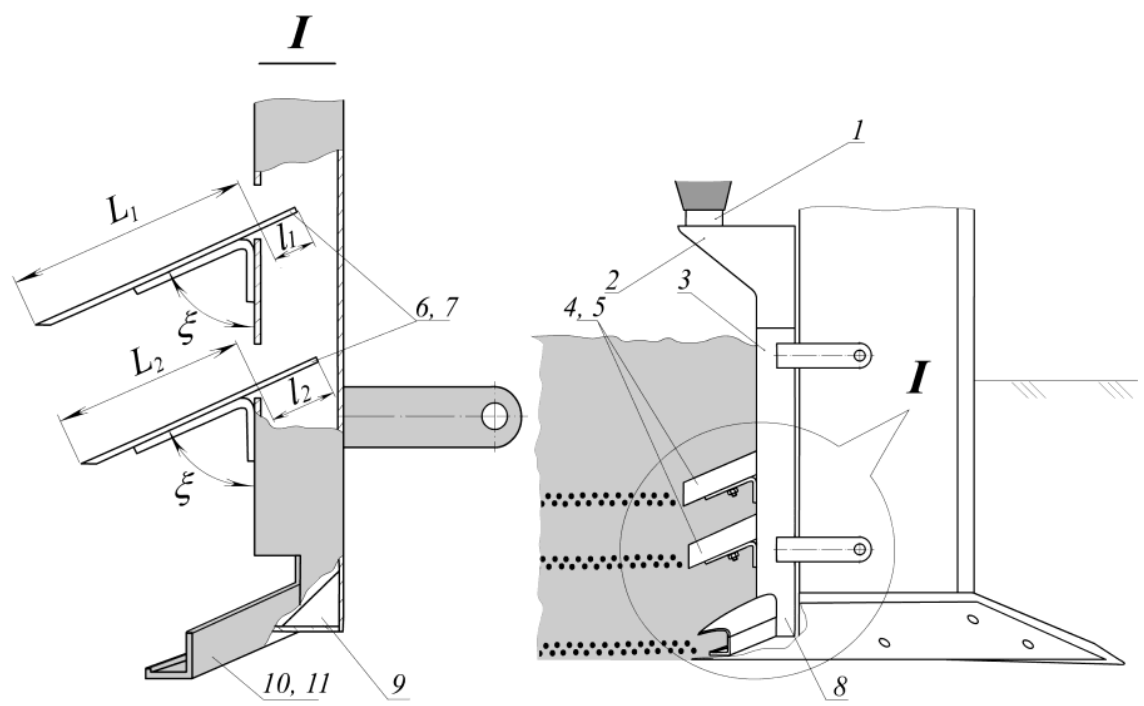

Fig. 1. Current distribution line for three-layer fertilizer application

The current distribution line of the ripper-fertilizer consists of a cylindrical part 1, to which the tool provider from the weighty apparatus is connected, an inclined funnel-shaped part 2, a concentrating flow of fertilizers, and a nutritionist channel 3 (Figure 1).

At the back of the current-carrying channel, two pipes 4 and 5 are installed in the form of a tray at an angle, providing free movement of granular fertilizers. Inside each branch 
pipe, movable reflective plates 6 and 7 are installed, which cut the fertilizers moving along the tool-conducting channel into parts, followed by their direction to the corresponding soil horizon. The reflective plates of the conductive channel do not completely block it, so some of the fertilizers enter the lower distributor of 8 [25-27].

It is known that the current line of the ripper-fertilizer must meet the following basic requirements: have a convenient layout behind the ripper working body of the ripper, ensure high-quality distribution of mineral fertilizers at specified depths [27].

\section{Results and Discussion}

The traction resistance of the ripper depends on the parameters of its elements and the physical and mechanical properties of the soil. The traction resistance of the ripper consists of the resistances of the bit, the ploughshare, and the rack with the tool provider

$$
P=P_{d}+2 P_{l}+P_{s t}
$$

where $P_{d}, P_{l}$, and $P_{s t}$ is respectively traction resistance of the bit, shield, and stands with tool provider.

The bit resistance can be determined from the following expression [29]

$$
\begin{gathered}
R_{d x}=\sigma_{o} \delta b_{d}+\frac{q b_{d} t_{d}^{2} \sin \left(\alpha_{d}+\beta_{f}\right) \sin \left(\alpha_{d}+\beta_{f}+\varphi\right)}{2 \sin ^{2} \beta_{f} \cos \varphi}+\tau \frac{a}{\sin \psi} \times \\
\times\left(b_{d}+K \frac{\operatorname{actg} \psi_{1}}{\sin \psi}\right)\left[\cos \psi+f \sin \left(\alpha_{d}+\psi\right) \cos \alpha_{d}\right]+ \\
+\gamma a\left[b_{d} V^{2} \sin \alpha_{d} \operatorname{tg}\left(\alpha_{d}+\varphi\right)+g l_{d}\left(b_{d}+\operatorname{actg} \psi_{1}\right)\left(\frac{1}{2} \sin \alpha_{d}+\right.\right. \\
\left.\left.+f \cos ^{2} \alpha_{d}\right)\right]\left(1+\frac{W}{100}\right) ;
\end{gathered}
$$

where $\sigma_{0}$ is a temporary soil resistance to crushing blade chisels, $\mathrm{Pa} ; \delta$ is the thickness of the blade, $\mathrm{m} ; b_{d}$ is width chisels, $\mathrm{m} ; \beta_{f}$ is angle sharpening chisels, $\alpha_{d}$ is installation angle of the bit to the horizon, $\alpha_{d} \psi$ is angle to the longitudinal shearing of the soil deg; $f$ is coefficient of friction of the soil on metal; $\gamma$ is the soil density, $\mathrm{kg} / \mathrm{m} 3 ; W$ is soil moisture, $\% ; \tau$ is the ratio of pure shear; $K$ is coefficient that takes into account the collapse of the peaks shift of the layer $K=0,5 ; V$ is the speed of the cultivator, $\mathrm{m} / \mathrm{s}$.

The resistance of the ploughshare consists of the following components

$$
P_{l}=P_{s}+P_{p}+P_{v}
$$

where $P_{s}$ is the resistance due to the deformation of the soil; $P_{p}$ is the resistance due to the mass of the soil layer; $p_{v}$ is the resistance due to the inertia force of the soil layer.

The forces expended on the deformation of the soil by the ploughshare are determined by projecting the forces $S$ and $T$ on the X-axis, where $S$ is the shear force of the soil; $T$ is the friction force arising from the force $S[30]$.

$$
\sum X=P_{s}-S_{x}-T_{x}=\mathrm{O}
$$




$$
P_{s}=\frac{K_{1} F_{s}}{2}\left[\cos \varphi_{1} \sin \gamma+f \sin \left(\alpha+\varphi_{1}\right)\left(\cos ^{2} \gamma+\sin ^{2} \gamma \cos \alpha\right)\right]
$$

where $F_{s}$ is the area of soil cleavage, $\mathrm{m}^{2}$.

$$
F_{s}=\left(b_{l}+\operatorname{actg} \psi_{1}\right) \operatorname{actg} \psi_{1} .
$$

The force $P_{p}$ of the reservoir weight is determined using the equation derived by G.Sineokov [29]

$$
P_{p}=m g \frac{\sin \alpha+f(\cos \alpha c t g \alpha+\sin \alpha \cos \alpha)}{\cos \alpha-f \sin \gamma \sin \alpha}
$$

where $m$ is the mass of the soil on the ploughshare, $\mathrm{kg}$;

$$
m=0.5 F_{1} \gamma l
$$

where $l$ is the length of the working surface of the ploughshare, cm; $F_{1}$ is the crosssectional area of the treated part of the formation, $\mathrm{m}^{2}$.

$$
F_{1}=b_{l} a+\frac{a^{2} \operatorname{ctg}^{2} \psi}{2}
$$

где $\varphi$ is soil external friction angle, ${ }^{\circ} \mathrm{C}$. form

Taking into account the expressions defining $\mathrm{m}$, the formula (7) will take the following

$$
P_{p}=\frac{1}{2} F_{1} \gamma g l \frac{\sin \alpha+f(\cos \gamma c t g \gamma+\sin \gamma \cos \alpha)}{\cos \alpha-f \sin \gamma \sin \alpha} .
$$

The soil resistance associated with the change in the velocity of the formation movement on the working surface of the ploughshare is determined similarly to the equation of G. Sineokov [28]

$$
P_{v}=\frac{1}{2} F_{1} \gamma V^{2} \frac{\sin ^{2} \gamma\left[\sin \alpha+f \sin \gamma\left(\operatorname{ctg}^{2} \gamma+\cos \alpha\right)\right]}{\operatorname{ctg} \alpha-\sin \gamma},
$$

where $\alpha$ is the corner of the crumbling of the blade, hail; $\gamma$ is angle solution paws deg; $f$ is coefficient of friction of the soil on the working surface of the blade; $V$ is velocity of the blade, $\mathrm{m} / \mathrm{s} ; \gamma$ is density of topsoil, $\mathrm{kg} / \mathrm{m}^{3}$.

Substituting the values found in formula (3), we find the traction resistance of the ploughshare 


$$
\begin{aligned}
& P_{l}=\frac{K_{1} F_{c}}{2}\left[\cos \varphi_{1} \sin \gamma+f \sin \left(\alpha+\varphi_{1}\right)\left(\cos ^{2} \gamma+\sin ^{2} \gamma \cos \alpha\right)\right]+ \\
& +\frac{F \gamma}{2}\left\{g l \frac{\sin \alpha+f(\cos \gamma c t g \gamma+\sin \gamma \cos \alpha)}{\cos \alpha-f \sin \gamma \sin \alpha}+V^{2} \frac{\sin ^{2} \gamma\left[\sin \alpha+f \sin \gamma\left(c t g^{2} \gamma+\cos \alpha\right)\right]}{\cos \alpha-f \sin \gamma}\right\} .
\end{aligned}
$$

Analysis of equation (11) shows that with the increase in the area of soil loosening, the traction resistance of the blade increases, it also depends on the settings blade (width $b_{l}$, angles of the solution and crumbling, the depth of $a$ turn, the speed of movement $V$ ) and physico-mechanical properties of the soil.

To simplify the formula (11), we introduce the following:

$$
\begin{gathered}
E_{1}=\left[\cos \varphi_{1} \sin \gamma+f \sin \left(\alpha+\varphi_{1}\right)\left(\cos ^{2} \gamma+\sin ^{2} \gamma \cos \alpha\right)\right] \\
E_{2}=\frac{\sin \alpha+f(\cos \gamma \operatorname{ctg} \gamma+\sin \gamma \cos \alpha)}{\cos \alpha-f \sin \gamma \sin \alpha} \\
E_{3}=\frac{\sin ^{2} \gamma\left[\sin \alpha+f \sin \gamma\left(\operatorname{ctg}^{2} \gamma+\cos \alpha\right)\right]}{c t g \alpha-f \sin \gamma}
\end{gathered}
$$

Finally, we get

$$
P_{\jmath}=\frac{1}{2} K_{1} F_{c} E_{1}+\frac{F_{1} \gamma}{2}\left(g l E_{2}+V^{2} E_{3}\right) .
$$

Substituting in the formula (15) the values of $K_{c}=3270 \mathrm{~Pa}, a=0.35 \mathrm{~m}, \alpha=20^{\circ}, f=0.5$ [26], we plot the change in the traction resistance of the soil from the width of the ploughshare.

When the width of the ploughshare is reduced from $50 \mathrm{~cm}$ to $30 \mathrm{~cm}$, the traction resistance of the ploughshare is reduced by $2.3 \mathrm{kN}$ or by $24.8 \%$. This allows you to aggregate the ripper-fertilizer with a Class 4 tractor.

To determine the traction resistance of the rack with the current line, consider the interaction of the soil with the rack and the current line in the cross-section of the horizontal plane (Figure 2).

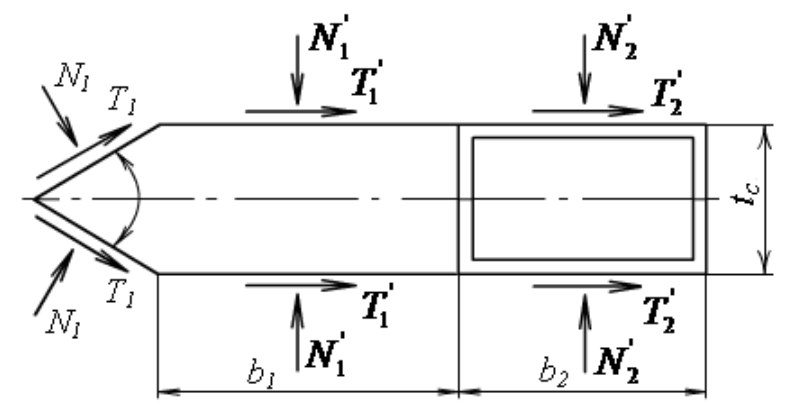

Fig. 2. Diagram of the forces acting on the rack and on the tool provider

On the frontal and side surfaces of the rack and the current line, when moving, there is a normal force $T_{y}$, which causes a friction force $T_{y}$. Projecting all the forces on the $X$-axis, we 
determine the traction resistance of the rack with the current line, which arises from the movement of the soil.

Given that $N_{i}=T_{i} f=T_{i} \operatorname{tg} \varphi$, we get

$$
P_{\mathrm{st}}=2\left(N_{1} \sin \beta_{1}+N_{1} f \cos \beta_{1}+N_{1}^{1} f+N_{2}^{1} f\right)
$$

After the transformations, we get

$$
P_{\mathrm{st}}=\frac{2}{\cos \varphi}\left(N_{1} \sin \left(\beta_{1}+\varphi\right)+\left(N_{1}^{1}+N_{2}^{1}\right) \sin \varphi\right)
$$

where $N_{1}$ is the force acting on the tapered face of the rack, $\mathrm{N} ; \beta_{1}$ is wedge angle, deg; $N_{1}{ }^{1}, N_{2}{ }^{1}$ are forces acting on a flat cheek rack and tool provider-rail, $\mathrm{N}$.

To determine the normal pressure $N_{i}$ on the frontal surface of the rack, we use the formula proposed by V.Levenets [28]. Dynamic and static forces act on the pointed face of the rack, which is determined by the following formulas

$$
\begin{aligned}
& N_{1 g}=\rho l_{s t} h V_{1}^{2} \sin ^{2} \beta_{1}, \\
& N_{1 s t}=\rho g \frac{l_{s t} h^{2}}{2 \operatorname{tg} \gamma_{1}} \cos \gamma_{1}
\end{aligned}
$$

or

$$
N_{1}=\rho l_{s t} h V^{2} \sin ^{2} \beta_{1}+\rho g \frac{l_{s} h^{2}}{2 \operatorname{tg} \gamma_{1}} \cos ^{2} \gamma_{1}\left(\operatorname{tg} \gamma_{1}+\operatorname{tg} \varphi_{1}\right),
$$

where $\rho$ is soil density, $\mathrm{kg} / \mathrm{m} 3 ; l_{s t}$ is taper length of the strut, $\mathrm{m} ; \gamma_{1}$ is angle of repose of the soil, degree; $\varphi_{1}$ is angle of internal friction of the soil, grad.

On the flat face of the rack with tool provider valid static power, which is determined by the formula

$$
N_{1}^{1}+N_{2}^{1}=\rho g \frac{\left(b_{1}+b_{2}\right) h^{2}}{2 \operatorname{tg} \gamma_{1}} \cos ^{2} \gamma_{1}\left(\operatorname{tg} \gamma_{1}+\operatorname{tg} \varphi_{1}\right)
$$

Taking into account the values of the forces $N_{1}, N_{1}{ }^{1}$, and $N_{2}{ }^{1}$, we finally get

$$
\begin{aligned}
& P_{s t}=\frac{2}{\cos \varphi}\left(\rho l_{c} h V^{2} \sin ^{2} \beta_{1} \sin \left(\beta_{1}+\varphi\right)+\rho g \frac{l_{c} h^{2}}{2 \operatorname{tg} \gamma_{1}} \cos \gamma_{1}\left(\operatorname{tg} \gamma_{1}+\operatorname{tg} \varphi_{1}\right) \sin \left(\beta_{1}+\varphi\right)+\right. \\
& \left.+\rho g \frac{\left(b_{1}+b_{2}\right) h^{2}}{2 \operatorname{tg} \gamma_{1}} \cos ^{2} \gamma_{1}\left(\operatorname{tg} \gamma_{1}+\operatorname{tg} \varphi_{1}\right) \sin \varphi\right) .
\end{aligned}
$$

Total tractive resistance of the cultivator with tool provider allocator will be equal to 


$$
\begin{gathered}
P=P_{\mathrm{d}}+2 P_{l}+P_{\mathrm{st}}=\sigma_{o} \delta b_{d}+\frac{q b_{d} t_{d}^{2} \sin \left(\alpha_{d}+\beta_{f}\right) \sin \left(\alpha_{d}+\beta_{f}+\varphi\right)}{2 \sin ^{2} \beta_{f} \cos \varphi}+\tau \frac{a}{\sin \psi} \times \\
\times\left(b_{d}+K \frac{a c t g \psi_{1}}{\sin \psi}\right)\left[\cos \psi+f \sin \left(\alpha_{d}+\psi\right) \cos \alpha_{d}\right]+ \\
+\gamma a\left[b_{d} V^{2} \sin \alpha_{d} \operatorname{tg}\left(\alpha_{d}+\varphi\right)+g l_{d}\left(b_{d}+a \operatorname{ctg} \psi_{1}\right)\left(\frac{1}{2} \sin \alpha_{d}+\right.\right. \\
\left.\left.+f \cos ^{2} \alpha_{d}\right)\right]\left(1+\frac{W}{100}\right)+K_{s} F_{s} E_{1}+\left(F_{1}^{1} \gamma_{1}+F_{1} \gamma_{2}\right)\left(g l_{1} E_{2}+V^{2} E_{3}\right)+ \\
+\frac{2 \rho h K_{3}}{\cos \varphi}\left(l_{s t} V^{2} \sin ^{2} \beta_{1} \sin \left(\beta_{1}+\varphi\right)+\frac{g h}{2 \operatorname{tg} \gamma_{1}} \cos ^{2} \gamma_{1}\left(\operatorname{tg} \gamma_{1}+\operatorname{tg} \varphi_{1}\right)\left(l_{s} \sin \left(\beta_{1}+\varphi\right)+2\left(b_{1}+b_{2}\right) \sin \varphi\right)\right),
\end{gathered}
$$

where $F_{c}$ is the area of cleavage of the soil, $\mathrm{m}^{2} ; K_{c}$ is the specific resistance of the soil of the subsurface layer to shear.

Calculations based on the formula (21), (22), (23), it was shown that the traction resistance of the current line is $12-12.5 \%$ of the traction resistance of the rack and $4-5 \%$ of the total traction resistance of the working body of the ripper.

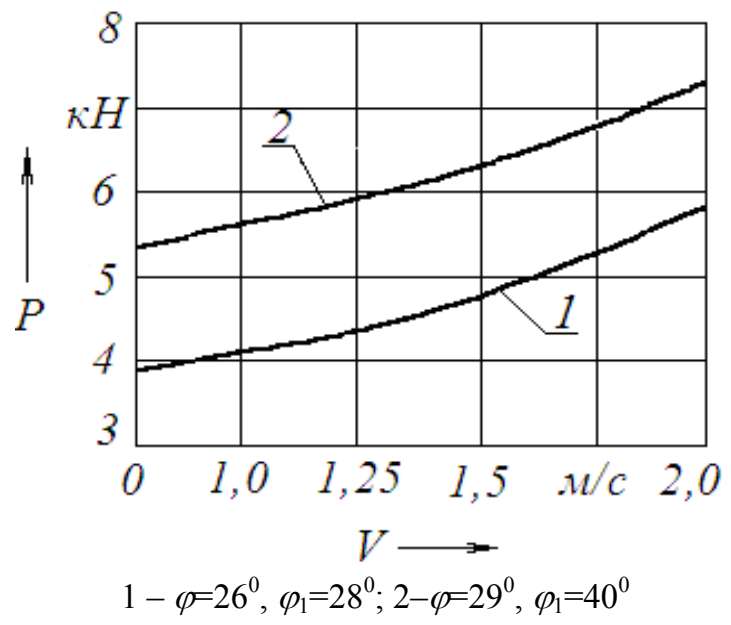

Fig. 3. Traction resistance of the working body of the ripper with a tool provider -distributor, depending on the speed of movement

Graphical interpretation of the mathematical model (23) on a computer (Fig.3) shows that with an increase in the speed of movement of the working body of the ripper with the tool provider-distributor, the traction resistance increases in a curved relationship. Thus, at $V=1.0 \mathrm{~m} / \mathrm{s}, \varphi_{1}=28^{\circ}$, the traction resistance was $4.11 \mathrm{kN}$, and at $V=2.0 \mathrm{~m} / \mathrm{s}, \varphi_{1}=28^{\circ} P=5.86$ $\mathrm{kN}$.

The traction resistance also increases with an increase in the internal friction coefficient of the soil $\varphi_{1}$. For example, at $V=1.0 \mathrm{~m} / \mathrm{s}, \varphi_{1}=28^{\circ} P=4.11 \mathrm{kN}$, and at $\mathrm{V}=1.0 \mathrm{~m} / \mathrm{s}, \varphi_{1}=40^{\circ}$ and $P=5.61 \mathrm{kN}$. These dependencies can be used to determine the traction resistance at various parameters of the working body of the ripper, the physical and mechanical properties of the soil, and the speed of movement.

\section{Conclusions}

1. Analytical dependences for determining the traction resistance of the working body of a ripper with a tool provider-distributor are obtained. It is established that the traction 
of the working body of the cultivator with tool provider allocator depends on the physic mechanical properties of the soil, thickness of the blade and the blade length of the bit length of the working surface of the blade, the angle of chopping and solution of the blade, width of capture and speed.

2. It is established that the traction resistance of the current line is $12-12.5 \%$ of the traction resistance of the rack and 4-5\% of the total traction resistance of the working body of the ripper.

\section{References}

1. Mamatov, F.M., Eshdavlatov, E., Suyunov, A. The Shape of the Mixing Chamber of the Continuous Mixer // Jour of Adv Research in Dynamical \& Control Systems, Vol. 12, 07-Special Issue, (2020). DOI: 10.5373/JARDCS/V12SP7/20202318 ISSN 1943023X.

2. Mamatov, F., Ergashev, I., Ochilov, S., Pardaev, X. Traction Resistance of Soil Submersibility Type "Paraplau" // Jour of Adv Research in Dynamical \& Control Systems, Vol.12, 07-Special Issue, (2020). DOI: 10.5373/JARDCS/V12SP7/20202336 ISSN1943-023X.

3. Aldoshin, N., Mamatov, F., Ismailov, I., Ergashov, G. Development of combined tillage tool for melon cultivation // 19th international scientific conference engineering for rural development Proceedings, Jelgava, 20.-22.05.(2020). Volume 19. ISSN 16915976. DOI:10.22616/ERDev.2020.19.TF175.

4. Umurzakov, U., Mirzaev, B., Mamatov, F., Ravshanov, H., Kurbonov, S. A rationale of broach-plow's parameters of the ridge-stepped ploughing of slopes // XII International Scientific Conference on Agricultural Machinery Industry IOP Conf. Series: Earth and Environmental Science 403(2019) 012163 IOP Publishing doi:10.1088/1755-1315/403/1/012163.

5. Mirzaev, B., Mamatov, F., Chuyanov, D., Ravshanov, X., Shodmonov, G., Tavashov, $\mathrm{R}$ and Fayzullayev, X. Combined machine for preparing soil for cropping of melons and gourds // XII International Scientific Conference on Agricultural Machinery Industry. doi.org/10.1088/1755-1315/403/1/012158.

6. Mirzaev, B., Mamatov, F., Ergashev, I., Ravshanov, H., Mirzaxodjaev, Sh., Kurbanov, Sh., Kodirov, U and Ergashev, G. Effect of fragmentation and pacing at spot ploughing on dry soils // E3S Web of Conferences 97. doi.org/10.1051/e3sconf/201913501065.

7. Mamatov, F., Mirzaev, B., Shoumarova, M., Berdimuratov, P., Khodzhaev, D. Comb former parameters for a cotton seeder// International Journal of Engineering and Advanced Technology (IJEAT) Volume-9 Issue1 October/ DOI: 10.35940/ijeat.A2932.109119.

8. Mamatov, F., Mirzaev, B., Batirov, Z., Toshtemirov, S., Tursunov, O., Bobojonov, L. Justification of machine parameters for ridge forming with simultaneous application of fertilizers // CONMECHYDRO - 2020 IOP Conf. Series: Materials Science and Engineering 883(2020) $012165 \quad$ IOP Publishing. doi:10.1088/1757$899 X / 883 / 1 / 012165$.

9. Mirzaev, B., Mamatov, F., Avazov, I., Mardonov, S. Technologies and technical means for anti-erosion differentiated soil treatment system// E3S Web of Conferences. doi.org/10.1051/e3sconf/20199705036.

10. Aldoshin, N., Didmanidze, O., Mirzayev, B., Mamatov, F. Harvesting of mixed crops by axial rotary combines // Proceeding of $7^{\text {th }}$ International Conference on Trends in Agricultural Engineering 2019. $17^{\text {th }}-20^{\text {th }}$ Prague, Czech Republic. - pp.20-26. September (2019)

11. Mirzaev, B., Mamatov, F., Aldoshin, N and Amonov, M. Anti-erosion two-stage 
tillage by ripper// Proceeding of 7th International Conference on Trends in Agricultural Engineering 17th-20th. Czech Republic. - pp.391-396. September (2019).

12. Mirzaev, B., Mamatov, F., Ergashev, I., Islomov, Yo., Toshtemirov, B., Tursunov O. Restoring degraded rangelands in Uzbekistan // Procedia Environmental Science, № 6. - pp 395-404. (2019).

13. Uzakov, Z.U., Mamatov, F.M., Begulov, O. Implementation of object-oriented Programming technology in the one-dimensional oil displacement problem // International Conference on information Science and Communications Technologies: ICISCT 2019/0012008. Tashkent, Uzbekistan. INSPEC Accession Number: 19412491. DOI: 10.1109/ICISCT47635.2019.9012008.

14. Mamatov, F., Mirzaev, B., Berdimuratov, P., Turkmenov, Kh., Muratov, L., Eshchanova, G. The stability stroke of cotton seeder moulder // CONMECHYDRO 2020. IOP Conf. Series: Materials Science and Engineering 883 (2020) 012145 IOP Publishing. doi:10.1088/1757-899X/883/1/012145.

15. Mamatov, F., Mirzaev, B., Tursunov, O. A Justification of Broach-Plow's Parameters of the Ridge-Stepped Ploughing // E3S Web of Conferences 97, 05035 (2019). doi.org/10.1051/e3sconf/20199705035.

16. Ahmedov, B.J., Mirzaev, B.S.,Mamatov, F.M., Khodzhaev, D.A., Julliev, M.K. Integrating of gis and gps for ionospheric perturbations in d- And f-layers using vlf receiver // InterCarto, InterGIS 26, - c. 547-560. DOI: 10.35595/2414-9179-2020-1-26547-560.

17. Mamatov, F., Mirzaev, B., Tursunov, O., Ochilov, S and Chorieva, D. Relief, physicomechanical and technological properties of soil in the cotton growing area // ICECAE 2020. IOP Conf. Series: Earth and Environmental Science 614(2020) 012169. IOP Publishing. doi:10.1088/1755-1315/614/1/012169.

18. Shamsutdinov, Z., Ubaydullaev, Sh., Shamsutdinov, N., Mirzaev, B., Mamatov, F., and Chorshabiyev, N. The concept of the phytogenic field: theory, research experience and practical significance // ICECAE 2020. IOP Conf. Series: Earth and Environmental Science 614(2020) 012164. IOP Publishing. doi:10.1088/1755-1315/614/1/012164.

19. Umurzakov, U., Mamatov, F., Aldoshin, N., and Mirzaev, B. Exploration of tillage technologies in the Republic of Uzbekistan // ICECAE 2020 IOP Conf. Series: Earth and Environmental Science 614(2020) 012168. IOP Publishing. doi:10.1088/1755$1315 / 614 / 1 / 012168$.

20. Mamatov, F., Aldoshin, N., Mirzaev, B., Ravshanov, H., Kurbanov, Sh and Rashidov, N. Development of a frontal plow for smooth, furless plowing with cutoffs // IPICSE 2020. IOP Conf. Series: Materials Science and Engineering 1030 (2021) 012135 IOP Publishing. doi:10.1088/1757-899X/1030/1/012135.

21. Mamatov, F., Mirzaev, B., Mirzahodzhaev, Sh., Uzakov, Z and Choriyeva, D. Development of a front plow with active and passive working bodies // IPICSE 2020. IOP Conf. Series: Materials Science and Engineering 1030 (2021) 012164. IOP Publishing. doi:10.1088/1757-899X/1030/1/012164.

22. Mamato, F.M., Eshdavlatov, E., Suyuno, A. Continuous Feed Mixer Performance //Journal of Advanced Research in Dynamical and Control Systems (JARDCS). Volume-12, 07-Spesia1 Issue, 2020. DOI: 10.5373/JARDCS/V12SP7/20202343. ISSN 1943-023X.

23. Mamatov, F., Ergashev, I., Mirzaev, B., Pardaev, X, Chorieva, D. Research of the Penetration Process of the Frontal Plow // 2nd Bukittinggi International Conference on Education (BICED) 2020. Journal of Physics: Conference Series 1779 (2021) 012002. IOP Publishing. doi:10.1088/1742-6596/1779/1/012002.

24. Kodirov, U., Aldoshin, N., Ubaydullayev, Sh., Sharipov, E., Muqimov, Z and Tulaganov, B. The soil preparation machine for seeding potatoes on comb // 
CONMECHYDRO - 2020 IOP Conf. Series: Materials Science and Engineering 883(2020) 012143 IOP Publishing doi:10.1088/1757-899X/883/1/012143.

25. Ravshanov, Kh., Fayzullaev, Kh., Ismoilov, I., Irgashev, D., Mamatov, S. The machine for the preparation of the soil in sowing of plow crops under film // CONMECHYDRO - 2020 IOP Conf. Series: Materials Science and Engineering 883(2020) 012138 IOP Publishing doi:10.1088/1757-899X/883/1/012138.

26. Ravshanov, H, Babajanov, L, Kuziev, Sh, Rashidov, N, Kurbanov, Sh. Plough hitch parameters for smooth tails// CONMECHYDRO - 2020 IOP Conf. Series: Materials Science and Engineering 883(2020) 012139 IOP Publishing doi:10.1088/1757899X/883/1/012139.

27. Chuyanov, D., Shodmonov, G.,Avazov, I., Rashidov, N, Ochilov, S. Soil preparation machine parameters for the cultivation of cucurbitaceous crops // CONMECHYDRO - 2020 IOP Conf. Series: Materials Science and Engineering 883(2020) 012139 IOP Publishing doi:10.1088/1757-899X/883/1/012122.

28. Mamatov F.M., Mirzaev B.S., Avazov I.Zh.. Agrotehnicheskie osnovy sozdanija protivojerozionnyh vlagosberegajushhih tehnicheskih sredstv obrabotki pochvy $\mathrm{v}$ uslovijah Uzbekistana // - Prirodoobustrojstvo, [In Russian]. (2014).

29. Mamatov F.M., Mirzaev B.S. Erosion preventive technology of crested ladder-shaped tillage and plow design // European Applied Sciences.- pp. 71-73. Stuttgart (Germany), (2014).

30. Lobachevskij Ja.P., Mamatov F., Jergashev I.T. Frontal'nyj plug dlja hlopkovodstva // - Hlopok, № 6.- 35-37 str. [In Russian]. (1991).

31. Mamatov F.M., Batirov Z.L., Khalilov M.S., Kholiyarov J.B. Three-Tiered Fertilizer Application with a Spreading Funnel of a Subsoil Tiller. Agricultural Machinery and Technologies. (2019);13(4):48-53. (In Russ.) doi: 10.22314/2073-7599-2019-13-4-4853.

32. Lichman G.I., Lichman A.A. Assessment of the impact of fertilizer application on crop yields. N5. pp. 16-21. [In Russian]. (2017).

33. Batirov Z., Toirov I., Boymuratov F., Sharipov Sh. Layered application of mineral fertilizers with the coulter ripper of a combined unit//IOP Conf. Series: Materials Science and Engineering 1030 (2021).doi: 10.1088/1757-899X/1030/1/012168.

34. Mamatov F., Mirzaev B., Batirov Z., Toshtemirov S., Tursunov O., Bobojonov L. Justification of machine parameters for ridge forming with simultaneous application of fertilizers. //IOP Conf. Series: Materials Science and Engineering 883 (2020). IOP Publishing doi:10.1088/1757-899X/883/1/012165

35. Mamatov F.M., Batirov Z.L, Xalilov M.S.Chizel-cultivator fertilizer for forming ridges and applying fertilizers. European Sciences review scientific journal. - №3-4. - pp. 267-270. (2018).

36. Mamatov F.M., Kodirov U.I. Energy-recourse machine for preparing soil for planting root crops on ridges. European Science Review.Vienna, N11. pp. 125-126. (2016).

37. Ahmetov A.A., Atakulov H.K., Allanazarov M.A., Inojatov I.A., Nurmihamedov B.U., UzakbergenovZh. K. Comprehensive research on the creation of combined tillage machines. 154. [In Russian]. Buhoro. (2012). 